\title{
Do Stabilization Exercises Increase the Effects of Lumbar Facet Radiofrequency Denervation?
}

\author{
Hatice CETIN, Nezire KOSE¹, Ceyhun TURKMEN', Esra DULGER, Sevil BILGIN¹, Altan SAHIN² \\ ${ }^{1}$ Hacettepe University, Faculty of Health Sciences, Department of Physiotherapy and Rehabilitation, Ankara, Turkey \\ ${ }^{2}$ Hacettepe University, Faculty of Medicine, Department of Anesthesiology and Pain Medicine, Ankara, Turkey \\ This study has been presented at the $10^{\text {th }}$ Congress of European Pain Federation between 6 and 9 September 2017 at Copenhagen, Denmark
}

Corresponding author: Hatice CETIN haticebitirim@hacettepe.edu.tr

\section{ABSTRACT}

AIM: To investigate the effects of lumbar stabilization exercises on pain severity, functional disability, and physical performance after two weeks following radiofrequency denervation in patients with lumbar facet joint syndrome (LFJS).

MATERIAL and METHODS: Thirty-nine patients diagnosed with LFJS and had radiofrequency denervation were assigned to study and control groups. The study group $(n=20)$ received a six-week stabilization exercise program and was informed about spine biomechanics, while the control group $(n=19)$ received only informations about spine biomechanics. Pain severity with visual analogue scale, perceived disability with Oswestry disability index, physical performance with physical performance tests and gait speed test were applied before and after radiofrequency denervation, and after six weeks of intervention program.

RESULTS: Despite the similar improvements were shown in terms of all outcomes in both groups following radiofrequency denervation ( $p>0.05$ ), the improvements were more in favor of study group after six week intervention program ( $<<0.05)$.

CONCLUSION: These results indicate that radiofrequency denervation is effective in improving the pain, disability, and physical performance in patients with LFJS and this effect is further enhanced by the stabilization exercises following this procedure. Adding stabilization exercises to radiofrequency denervation yielded positive outcomes and these exercise are strongly advised in physiotherapy and rehabilitation program.

KEYWORDS: Zygapophyseal joint, Spine, Radiofrequency denervation, Paraspinal muscles, Exercise

\section{- INTRODUCTION}

$\mathrm{L}$ umbar facet joint syndrome (FJS) has been described as a potential cause of low back pain and affects Jan estimated $4 \%$ to $8 \%$ of low back pain patients without neurological deficits or radiographic evidence of lumbar spine disease (13). FJS occurs as a result of loss of intervertebral disc integrity, which is the basic anatomic unit of the spinal column, and degenerative changes in facet joints, concomitantly. The levels of physical performance and functional disability of patients with lumbar FJS are affected because of the chronicity of the pain (17).
The treatment of lumbar FJS pain ideally consists of a multimodal approach comprising conservative therapy including physical therapy, medical management, procedural intervention, and, if indicated, surgical therapy (18).

Radio frequency denervation (RFD) is one of the procedural intervention methods used most commonly in the treatment of FJS. RFD aims to prevent the conduction of nociceptive impulses through the use of an electric current that damages the pain-conducting nerve (12). Numerous placebo-controlled trials have examined lumbar facet pain and demonstrated that RFD gives positive results in lumbar pain in appropriately selected patients $(6,19)$. Although RFD can be an effective

\begin{tabular}{llll}
\hline Hatice CETIN & (D) : 0000-0001-8488-5763 & Esra DULGER & (D) : 0000-0002-5756-5892 \\
Nezire KOSE & (D) : 0000-0001-8342-7293 & Sevil BILGIN & (D) : 0000-0003-1597-1312 \\
Ceyhun TURKMEN & (D) : :0000-0002-3125-4113 & Altan SAHIN & (D) : 0000-0003-2766-2015
\end{tabular}


tool to provide clinically significant improvements in pain and disability in patients with lumbar facet joint pain, it is not a permanent solution. Pain usually recurs and RFD may need to be repeated (21). The authors of a review have also indicated that no high quality studies have been published showing that RFD provides pain relief for patients with chronic low back pain (15).

The lumbar stabilization exercises approach, which is one of the exercise approaches in physical therapy, is of great importance in decreasing impairments for controlling painrelated spinal structures and ensuring the sufficient stability of the lumbar spine (8). These exercises are based on control of the local muscle system (multifidus, transversus abdominis, diaphragm, and pelvic floor muscles) responsible for ensuring segmental stability of the vertebral column (7). Without local muscle control, abnormal segmental movement occurs, resulting in clinical instability. The exercises developed to improve the already disrupted motor control depend on the fact that local muscle activation stabilizes the lumbar spine occurring prior to every movement or perturbation of the body (4). Clinical trials have shown that stabilization exercises reduce pain, improve physical performance, and prevent recurrent low back pain by strengthening muscles supporting the vertebral column (10).

A gap in knowledge exists regarding our understanding of the acute effects of stabilization exercises on pain, disability, and physical performance when applied after RFD. Therefore, the main objective of the present study was to examine the effects of stabilization exercises when started in the acute period in patients with lumbar FJS after RFD.

\section{MATERIAL and METHODS}

\section{Study Design and Participants}

Thirty-nine patients who were diagnosed with lumbar FJS and who were selected to undergo RFD by a specialist physician and met the inclusion criteria were enrolled. The patients were divided into two groups: study and control. After 2 weeks of RFD, the study group $(n=20)$ had 6-week exercise program and informations about lower back biomechanics; the control group $(n=19)$ had only informations about biomechanics. Exercise program included lumbar stabilization exercises was performed by physical therapist once a week and the patients were asked to repeat one more time at home. Following 6 -week intervention programs, the study was completed. A flow diagram of the study is shown in Figure 1.

The inclusion criteria were age greater than 45 years, failure to improve with conservative treatment, limited functions and daily living activities, and pain exacerbated by rest, sitting, or standing; the exclusion criteria were previous surgical intervention in the spine or hip, previous local injection to the lumbar spine facet joint, current treatment with a narcotic drug, and impairment of cognition or speech. Patients fulfilling these criteria were asked to give their written informed consent to participate in the study.
The Ethics Committee (GO 14/605) confirmed that the study adhered to the guidelines established by the Helsinki Declaration. No financial inducements were provided for participating in the study. The trial was registered at ClinicalTrials.gov (identifier: NCT03444493).

\section{Scales}

At the beginning of this study, detailed demographic information and characteristics was obtained, including sex, age, body mass index (BMI), occupation, education status, pain duration, and levels of RFD as well as medical information. After that, all patients were subjected to the first physiotherapy assessment before RFD. Then RFD was performed. Two weeks after the RFD, the second physiotherapy assessment was applied. After that, the intervention program was started. Six weeks after the intervention program, the third assessment was performed. The following assessments were included in this study:

\section{Visual Analog Scale (VAS)}

Patients were asked to mark their level of pain on a $10-\mathrm{cm}$ line at rest, during activity, and at night. The VAS was marked at one end with "no pain" and at the other with "worst pain imaginable" (5).

\section{Oswestry Disability Index (ODI)}

The ODI assesses ten different aspects of disability (pain, personal care, lifting, sitting, standing, sleeping, sex life, social life, walking, and travelling). Each parameter is scored from 0 to 5 , with 0 indicating no functional limitation due to pain and 5 indicating a major functional disability due to low back pain. This questionnaire is scored using a global percentage score. The obtainable maximum score is 50 , which corresponds to $100 \%$ (25).

\section{Physical Performance}

Eight physical performance tests of daily activities such as climbing stairs, picking up something from the floor, bending forward, rolling up from a supine position, putting on a sock, and standing up from a lying position were evaluated. The tests were observed by a trained physiotherapist, who judged the patients' individual performance in each test using four grades of movement quality that were recorded on a fourpoint ordinal scale (0: performs activity without any difficulty; 3: restricted movement, cannot perform activity) (20).

\section{Gait Speed}

Patients were asked to walk 10 meters as fast as possible. When the subject completed the walk, the timer was stopped. Ten-meter gait speed was measured and recorded in $\mathrm{m} / \mathrm{s}$.

\section{Intervention Program}

The intervention program included a home exercise program and back protection training. The 20 patients in the study group were given stabilization exercises and suggestions about protection of lumbar spine biomechanics. The 19 patients in the control group were only given these suggestions. 
Patients in the study group performed specific localized lumbar stabilization exercises aiming to restore the stabilization function of the transversus abdominis for 6 weeks. The exercises were designed specifically to activate and train the isometric holding function of the transversus abdominis muscle at the affected vertebral segment. The stabilization exercises were basically performed in 3 phases for the exercise group. In the first phase, effective and correct contraction of the transversus abdominis and multifidus muscles and how the patients should adapt their daily living activities were taught. In the second phase, protection of stabilization by counteracting more muscle activation was aimed, and in the third phase, neutral position along with activities requiring high level control (3). The home-based exercise programs of patients were rearranged according to their weekly check-ups. The patients were asked to perform the exercises 5 times a week for 6 weeks. They were also asked to record to their personal schedule for the days when they performed the exercises.

\section{Statistical Analysis}

Data analysis was performed using IBM SPSS Statistics, version 20 (IBM, New York, NY). Comparability of measurements between the two groups was assessed using Student's t-test for numerical variables and the Chi-square test for categorical variables to examine differences in all baseline measurements. One-way ANOVA for repeated measures followed by post hoc analysis using linear contrasts was performed to detect changes over time within the same group. Between-group comparisons of the responses were tested by two-way ANOVA factoring by group and time.The Mann-Whitney U-test was used for comparison of the study and control groups. Significance was set at $\mathrm{p}=0.05$.

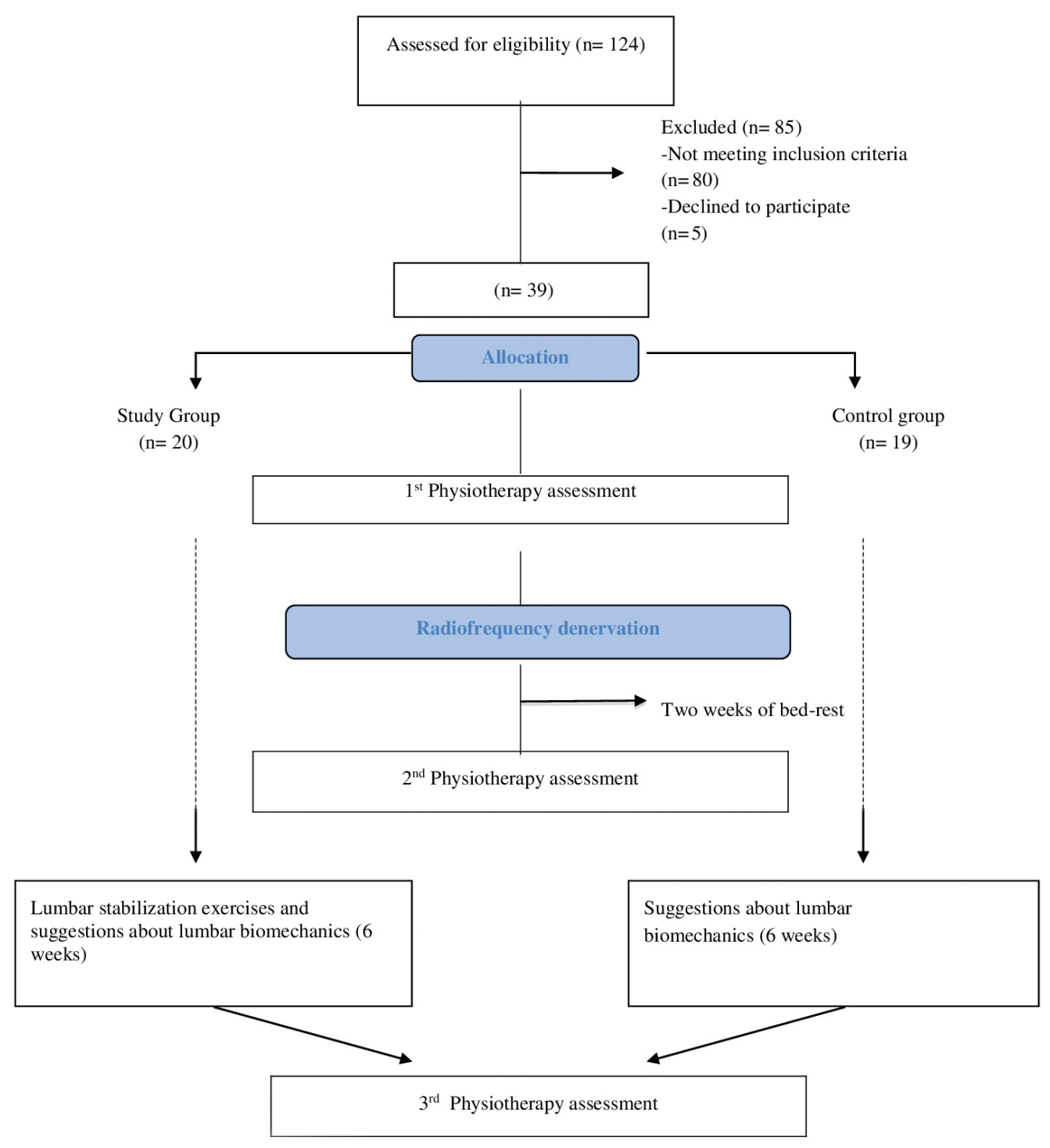

Figure 1: Flow chart of study participants. 


\section{RESULTS}

The statistical analyses revealed that the groups were homogeneous in terms of their demographic information and characteristics ( $p>0.05$ ) (Table l).

In this study, all assessments were performed 3 times, namely at the beginning of the study, before the intervention program (after 2 weeks following RFD), and after the intervention program. The results of these assessments were compared with each other.

At the beginning of the study, VAS ${ }_{\text {activity, }} V_{\text {night }}$, ODI, and physical performance test scores were not significantly different between the groups ( $p>0.05)$, but VAS $_{\text {rest }}$ and gait speed were different $(p<0.05)$. Two weeks after the RFD (before the intervention program), the assessment results were similar to those of the initial assessment except for the VAS night $_{\text {scores. }}$ VAS $_{\text {night }}$ results in this second evaluation differed between the groups $(\mathrm{p}<0.05)$ (Table II).

Additional analyses were performed to determine the amount of improvement within groups and between groups as well.
All the evaluation parameters in both groups had changed positively within groups $(\mathrm{p}<0.05)$ (Table II). When analyzed between group-comparisons factoring by group-time, the improvements in favor of study group (two-way ANOVA, $p<0.001)$. According to statistical analysis within groups, there was no significant improvement between the second and third assessments in the control group in all assessment parameters $(p>0.05)$. In the exercise group, this improvement continued, in contrast to the control group $(p<0.05)$ (Table III) (Figure 2A-F). This result prompted the question: what was the effect of the exercise program in the study group on this improvement? To understand this, the improvement status and the amounts of improvement in the second and third evaluations were analyzed (Table III, Table IV).

Amounts of improvement between the groups were also analyzed and the differences between the evaluation results of the groups were compared. The amounts of healing at the end of the study varied between the groups $(p<0.05)$, but no difference was found in the control group after RFD ( $p>0.05)$ (Table IV).

Table I: Baseline Participant Characteristics of Study Group and Control Group

\begin{tabular}{|c|c|c|c|}
\hline & $\begin{array}{c}\text { Study Group } \\
\text { X (SD) }\end{array}$ & $\begin{array}{c}\text { Control Group } \\
\text { X (SD) }\end{array}$ & $\mathbf{p}$ \\
\hline Age (year) & $55.50(9.0)$ & $57.79(8.6)$ & $0.42^{\mathrm{a}}$ \\
\hline Height $(\mathrm{cm})$ & $162.90(6.1)$ & $160.26(10.1)$ & $0.33^{a}$ \\
\hline Weight (kg) & $83.50(12.7)$ & $77.1(15.8)$ & $0.17^{\mathrm{a}}$ \\
\hline BMI $\left(\mathrm{kg} / \mathrm{m}^{2}\right)$ & 31.49 (3.6) & $30.13(3.8)$ & $0.39^{a}$ \\
\hline Pain duration (year) & $20.12(3.56)$ & $22.31(4.62)$ & $0.37^{\mathrm{a}}$ \\
\hline Previous conventional physiotherapy (week) & $3.25(2.59)$ & $3.84(3.17)$ & $0.45^{\mathrm{a}}$ \\
\hline & $\mathbf{n}$ & $\mathbf{n}$ & \\
\hline $\begin{array}{l}\text { Gender } \\
\text { Female } \\
\text { Male }\end{array}$ & $\begin{array}{r}15 \\
5\end{array}$ & $\begin{array}{r}15 \\
4\end{array}$ & $0.12^{\mathrm{b}}$ \\
\hline $\begin{array}{c}\text { RFD Level } \\
L_{1}-L_{5} \\
L_{2}-S_{1} \\
L_{3}-S_{1}\end{array}$ & $\begin{array}{r}5 \\
11 \\
4\end{array}$ & $\begin{array}{r}3 \\
13 \\
3\end{array}$ & $0.54^{b}$ \\
\hline $\begin{array}{l}\text { Education level (n) } \\
\text { Elementary school } \\
\text { Secondary school } \\
\text { High school } \\
\text { University }\end{array}$ & $\begin{array}{l}9 \\
4 \\
4 \\
3\end{array}$ & $\begin{array}{r}10 \\
3 \\
5 \\
1\end{array}$ & $0.62^{b}$ \\
\hline $\begin{array}{c}\text { Occupation (n) } \\
\text { Housewife } \\
\text { Retired } \\
\text { Working }\end{array}$ & $\begin{array}{r}13 \\
5 \\
2\end{array}$ & $\begin{array}{r}12 \\
0 \\
7\end{array}$ & $0.28^{b}$ \\
\hline
\end{tabular}

RFD: Radiofrequency denervation, BMI: Body Mass Index, SD: Standard Deviation.

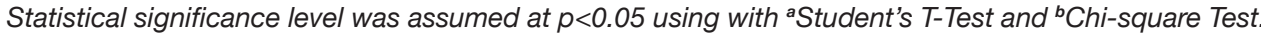


Table II: The Comparison of Outcome Measurements All of the Patients Between Groups

\begin{tabular}{|c|c|c|c|c|c|c|c|c|c|}
\hline & \multicolumn{3}{|c|}{$\begin{array}{c}\text { Before RFD } \\
\text { X (SD) }\end{array}$} & \multicolumn{3}{|c|}{$\begin{array}{c}\text { After RFD } \\
\text { (Before Intervention) X (SD) }\end{array}$} & \multicolumn{3}{|c|}{$\begin{array}{c}\text { After Intervention } \\
\text { X (SD) }\end{array}$} \\
\hline & $\begin{array}{l}\text { Study } \\
\text { X (SD) }\end{array}$ & $\begin{array}{l}\text { Control } \\
\text { X (SD) }\end{array}$ & $\mathbf{p}$ & $\begin{array}{l}\text { Study } \\
\text { X (SD) }\end{array}$ & $\begin{array}{l}\text { Control } \\
\text { X (SD) }\end{array}$ & $\mathbf{p}$ & $\begin{array}{l}\text { Study } \\
\text { X (SD) }\end{array}$ & $\begin{array}{l}\text { Control } \\
\text { X (SD) }\end{array}$ & $\mathbf{p}$ \\
\hline VAS $_{\text {rest }}$ & $6.72(1.4)$ & $8.12(2.4)$ & $0.03^{\star}$ & $4.51(3.4)$ & $6.21(2.32)$ & $<0.001^{*}$ & $1.45(2.0)$ & $5.23(2.3)$ & $<0.001^{*}$ \\
\hline VAS $_{\text {activity }}$ & $8.21(1.3)$ & $9.04(1.0)$ & 0.14 & $6.26(3.8)$ & $6.34(2.56)$ & 0.43 & $2.31(1.3)$ & $6.02(0.2)$ & $<0.001^{*}$ \\
\hline $10 \mathrm{MWT}\left(\mathrm{m} / \mathrm{s}^{2}\right)$ & $0.38(0.52)$ & $0.33(0.09)$ & $0.03^{*}$ & $0.44(0.46)$ & $0.37(0.10)$ & $0.02^{*}$ & $0.56(0.83)$ & $0.38(0.10)$ & $<0.001^{*}$ \\
\hline РPT(0-24) & $13.7(4.0)$ & 14.1(3.9) & 0.75 & $11.1(3.5)$ & $12.2(3.2)$ & 0.31 & $4.4(2.3)$ & $11.6(3.0)$ & $0.001^{*}$ \\
\hline
\end{tabular}

VAS: Visual Analog Scale, ODI: Oswestry Disability Index, MWT: Meter walking test, PPT: Physical performance tests, RFD: Radiofrequency denervation. " $p<0.05$ between group differences using Student's T-Test.

Table III: The Comparison of Outcome Measurements withina Groups

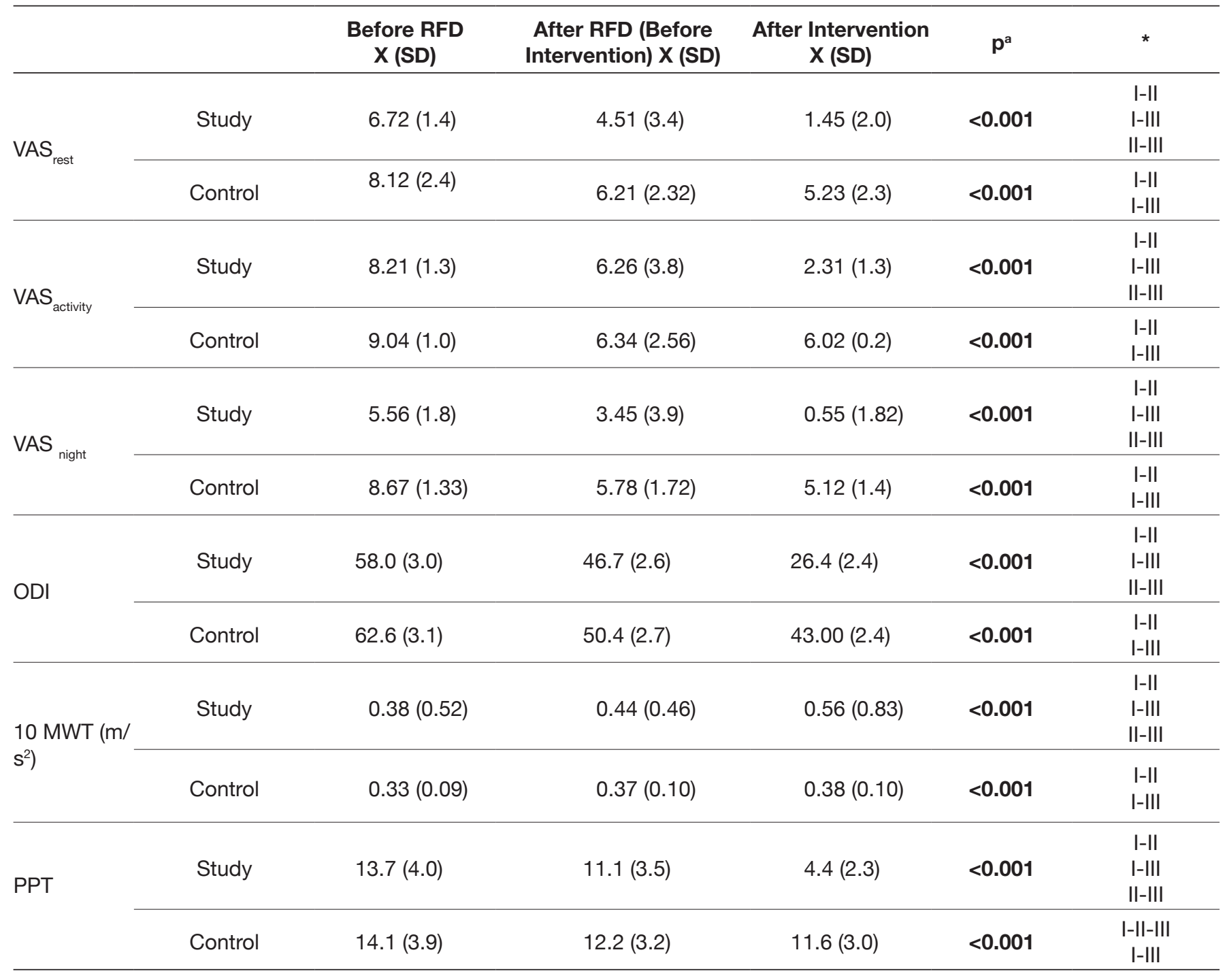

RFD: Radiofrequency denervation, I: Before RFD, II: After RFD (Before Intervention), III: After Intervention, VAS: Visual Analog Scale, ODI: Oswestry Disability Index, MWT: Meter walking test, PPT: Physical performance tests, $\boldsymbol{p}^{\text {a: }}$ Within group differences using One-way ANOVA Test, *: The groups that are differences between the each other. 
Table IV: The Comparison of the Differences Between Groups' Assessment Results

\begin{tabular}{|c|c|c|c|c|}
\hline & & Study X (SD) & Control X (SD) & $\mathbf{p}^{a}$ \\
\hline \multirow{3}{*}{ VAS $_{\text {rest }}$} & II-I & $1.60(1.60)$ & $2.0(1.97)$ & 0.12 \\
\hline & III-I & $4.15(2.10)$ & $2.52(1.67)$ & 0.01 \\
\hline & III-II & 2.55 (1.04) & $0.52(0.78)$ & $<0.001$ \\
\hline \multirow{3}{*}{ VAS $_{\text {activity }}$} & II-I & 1.95 (1.39) & $2.36(1.60)$ & 0.27 \\
\hline & III-I & $5.75(1.11)$ & $2.73(1.75)$ & $<0.001$ \\
\hline & III-II & $3.80(2.21)$ & $0.36(1.34)$ & $<0.001$ \\
\hline \multirow{3}{*}{ VAS $_{\text {night }}$} & II-I & $1.75(1.91)$ & $1.78(1.61)$ & 0.97 \\
\hline & III-I & $3.80(2.66)$ & $1.94(1.77)$ & 0.02 \\
\hline & III-II & $2.05(1.02)$ & $0.15(0.56)$ & $<0.001$ \\
\hline \multirow{3}{*}{ ODI } & II-I & $11.31(8.93)$ & $12.16(9.17)$ & 0.72 \\
\hline & III-I & 41.55 (12.77) & 13.08 (9.98) & $<0.001$ \\
\hline & III-II & $20.24(14.43)$ & $6.92(5.45)$ & $<0.001$ \\
\hline \multirow{3}{*}{$10 \mathrm{MWT}\left(\mathrm{m} / \mathrm{s}^{2}\right)$} & II-I & $0.05(0.03)$ & $0.04(0.02)$ & 0.46 \\
\hline & III-I & $0.17(0.09)$ & $0.04(0.03)$ & $<0.001$ \\
\hline & III-II & $0.11(0.07)$ & $0.01(0.02)$ & $<0.001$ \\
\hline \multirow{3}{*}{ PPT } & II-I & 2.55 (1.82) & $1.84(1.70)$ & 0.25 \\
\hline & III-I & $9.3(3.58)$ & $2.42(1.92)$ & $<0.001$ \\
\hline & III-II & $6.75(3.27)$ & $0.57(0.83)$ & $<0.001$ \\
\hline
\end{tabular}

I: Before RFD, II: After RFD (Before intervention), III: After intervention, VAS: Visual Analog Scale, ODI: Oswestry Disability Index, MWT: Meter walking test, PPT: Physical performance tests, $\boldsymbol{p}^{a}$ : Mann Whitney-U test.

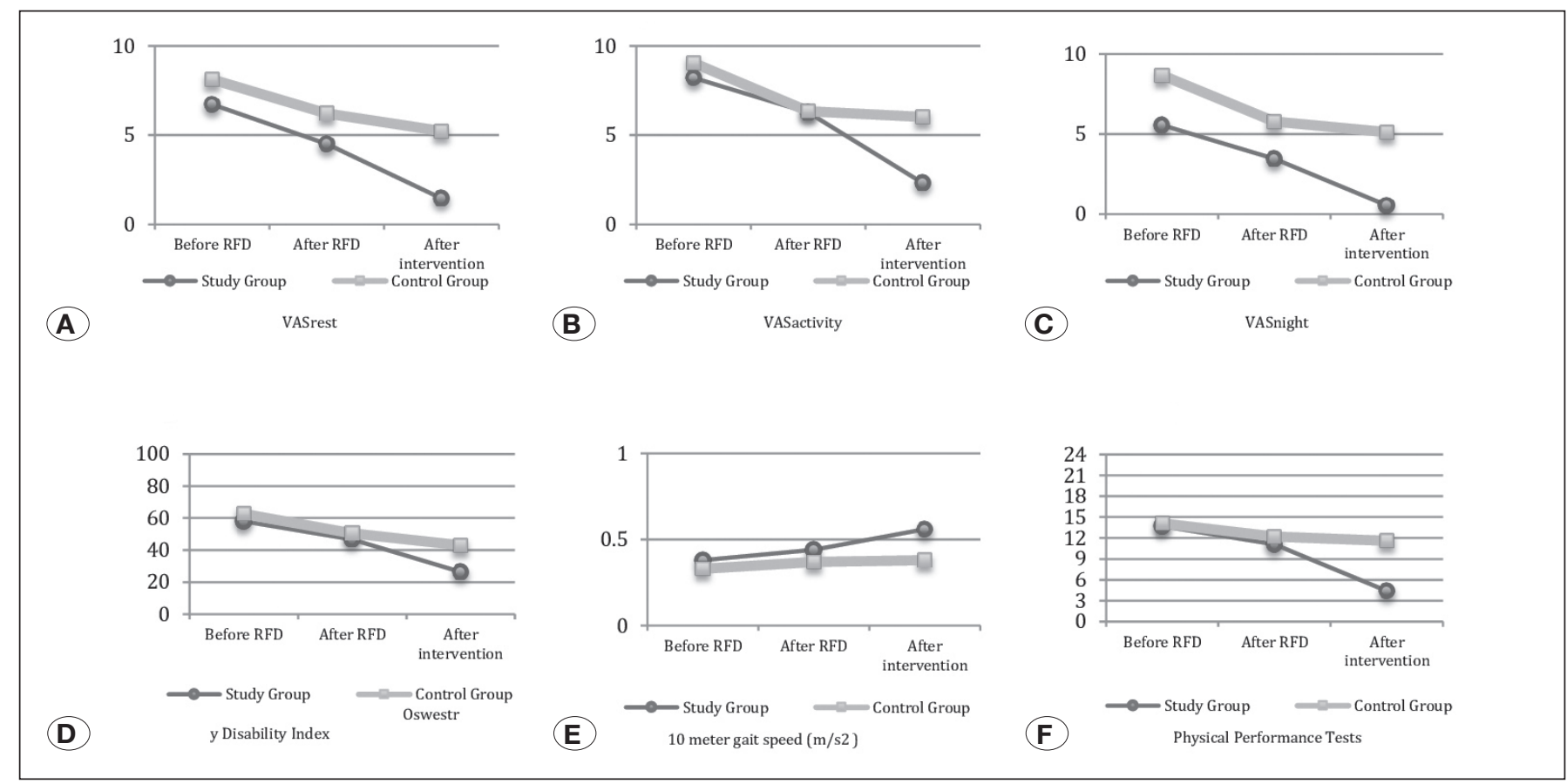

Figure 2: Clinical outcomes of study and control groups A) VASrest, B) VASactivity, C) VASnight scores significantly decreased between after RFD and after intervention, while VAS scores decreased similarly between before and after RFD in both groups. D) Oswestry Disability Index improved more than control group after intervention in the study group. E) 10 meter gait speed, F) Physical Performance Test scores represented as above (RFD: Radiofrequency denervation). 


\section{DISCUSSION}

At the end of this study, it was found that RFD had positive effects on pain disability, and physical performance in patients with lumbar FJS; these effects were mostly in the first 2 weeks. In addition, it was determined that the stabilization exercises, started two weeks after RFD and continued for six weeks, increased these positive effects as well.

The positive effects of RFD in our study are parallel to those in the literature. Dreyfuss et al. reported that of 15 patients that received RFD after 12 months of pain relief $60 \%$ achieved at least $90 \%$ relief and $87 \%$ at least $60 \%$ relief (9). Van Kleef et al. reported a higher success rate in the radiofrequency treatment group at 3, 6, and 12 months than in the control group that underwent the same procedure but without radiofrequency current (24). On the other hand, Leclaire et al. stated in their study comparing radiofrequency denervation and the same procedure without effective denervation (control group) that Roland-Morris scores improved by $8.4 \%$ and $2.2 \%$, respectively. At 12 weeks there was no significant difference in the Roland-Morris score, VAS, strength/mobility, or return to work between the groups (14). As is apparent, these positive effects in the literature do not seem to form a definite consensus on emergence and persistence. In our study, positive developments in our patients were greater in the first two weeks, and decreased in the following 6 weeks.

In our study, the effects of the intervention program, which began to be implemented 2 weeks after the RFD, were also examined in terms of continuing or increasing these positive effects of RFD. In this regard, it was found that back protecting training alone was not sufficient and in addition stabilization exercises improved this healing.

The segmental integrity and stability of the vertebral column are disturbed in FJS because the position of the facet joint relative to the sagittal and coronal planes plays an important role in protecting the joints against excessive motion of the spine (16). Through mechanical modeling, biomechanists have described whole body stability, elastic energy, and sufficient stability (adequate activation for functional movement) to define requirements for a stable spine (22). In addition to biomechanical concepts, motor control of the local muscles is also disturbed after an injury like FJS. It has been reported that reduced transversus abdominis and lumbar multifidus thickness change during contraction, delayed feed forward activation of these muscles during trunk or limb movement, and fat infiltration and muscle atrophy in lumbar multifidus (23).

Rehabilitation of these muscles with specific motor control exercises is necessary to enhance stability while protecting the spine from excessive loads in the rehabilitation program. Lumbar stabilization exercises are aimed at improving the neuromuscular control, endurance, and strength of the transversus abdominis, lumbar multifidus, diaphragmatic, and pelvic muscles central to maintaining dynamic spinal stability (1). Clinical trials showed that lumbar stabilization exercises affect pain and physical capacity positively for short-term and long-term effectiveness in low back patients (11).
Based on this information and our results, we think that lumbar stabilization exercises are very important in the treatment of lumbar FJS after RFD. Because pain usually recurs and RFD may need to be repeated, this interventional procedure is not typically a permanent solution for treatment of this patient population (2). However, there are no studies that suggest a limitation on how many times this procedure can be performed. Therefore, lumbar stabilization exercises immediately after RFD may be useful for reducing the necessity of RFD repetitions, because of strengthening local muscles. While patients could not perform exercises because of pain before RFD, they performed them more effectively with decreasing pain severity after RFD. Thus, patients may have greater achievements in terms of co-contraction skill perception of local muscles by using motor learning principles for gaining skill again.

There are many studies in the literature about chronic low back pain, but there are no specific exercise therapy studies after RFD in lumbar FJS. For this reason, we think that this study is the first to investigate the effect of an exercise program after RFD in lumbar FJS patients. However, in our study, only the early effects of RFD and stabilization exercises could be examined and longer duration effects could not be investigated. This is a limitation of our study. Thus, it has been concluded that the implementation of exercises in this area of spinal stabilization exercises, and even studies of longer follow-up results, will provide a significant benefit for lumbar FJS patients.

\section{CONCLUSIONS}

RFD is effective in improving the pain, disability, and physical performance seen in patients with lumbar FJS but this effect can be improved further by stabilization exercises applied after RFD.

\section{ACKNOWLEDGEMENTS}

This study was funded by the Scientific Research Project Coordination Unit, Hacettepe University, (Grant number MT2015-902).

\section{REFERENCES}

1. Akuthota V, Ferreiro A, Moore T, Fredericson M: Core stability exercise principles. Current Sports Medicine Reports 1:3944,2008

2. Barnsley L: Percutaneous radiofrequency neurotomy for chronic neck pain: Outcomes in a series of consecutive patients. Pain Medicine 6:282-286,2005

3. Barr KP, Griggs M, Cadby T: Lumbar stabilization: A review of core concepts and current literature, part 2. American Journal of Physical Medicine \& Rehabilitation 1:72-80,2007

4. Bickel CS, Yarar-Fisher C, Mahoney ET, McCully KK: Neuromuscular electrical stimulation-induced resistance training after SCl: A review of the dudley protocol. Top Spinal Cord Inj Rehabil 4:294-302, 2015 
5. Bodian CA, Freedman G, Hossain S, Eisenkraft JB, Beilin $Y$ : The visual analog scale for pain. Clinical significance in postoperative patients. The Journal of the American Society of Anesthesiologists 6:1356-1361,2001

6. Bogduk N: Evidence-informed management of chronic low back pain with facet injections and radiofrequency neurotomy. The Spine Journal 1:56-64,2008

7. Boucher JA, Preuss R, Henry SM, Dumas JP, Larivière C: The effects of an 8-week stabilization exercise program on lumbar movement sense in patients with low back pain. BMC Musculoskeletal Disorders 1:23,2016

8. Brumitt J, Matheson J, Meira EP: Core stabilization exercise prescription, part I: Current concepts in assessment and intervention. Sports Health 6:504-509,2013

9. Dreyfuss P, Halbrook B, Pauza K, Joshi A, McLarty J, Bogduk $\mathrm{N}$ : Efficacy and validity of radiofrequency neurotomy for chronic lumbar zygapophysial joint pain. Spine 10:12701277,2000

10. Hambraeus J, Hambraeus KS, Persson J: Radiofrequency denervation improves health-related quality of life in patients with thoracic zygapophyseal joint pain. Pain Medicine 5:914919,2017

11. Javadian Y, Akbari M, Talebi G, Taghipour-Darzi M, Janmohammadi $\mathrm{N}$ : Influence of core stability exercise on lumbar vertebral instability in patients presented with chronic low back pain: A randomized clinical trial. Caspian Journal of Internal Medicine 2:98,2015

12. Juch JN, Maas ET, Ostelo RW, Groeneweg JG, Kallewaard JW, Koes BW, Verhagen AP, van Dongen JM, Huygen FJ, van Tulder MW: Effect of radiofrequency denervation on pain intensity among patients with chronic low back pain: The Mint randomized clinical trials. Jama 1:68-81,2017

13. Kroll HR, Kim D, Danic MJ, Sankey SS, Gariwala M, Brown M: A randomized, double-blind, prospective study comparing the efficacy of continuous versus pulsed radiofrequency in the treatment of lumbar facet syndrome. Journal of Clinical Anesthesia 7:534-537,2008

14. Leclaire R, Fortin L, Lambert R, Bergeron YM, Rossignol M: Radiofrequency facet joint denervation in the treatment of low back pain: A placebo-controlled clinical trial to assess efficacy. Spine 13:1411-1416,2001
15. Maas ET, Ostelo RW, Niemisto L, Jousimaa J, Hurri $H$, Malmivaara A, van Tulder MW: Radiofrequency denervation for chronic low back pain. Cochrane Library 10, 2015

16. Masharawi Y, Rothschild B, Dar G, Peleg S, Robinson D, Been E, Hershkovitz I: Facet orientation in the thoracolumbar spine: Three-dimensional anatomic and biomechanical analysis. Spine 29(16):1755-1763, 2004

17. McCormick ZL, Marshall B, Walker J, McCarthy R, Walega DR: Long-term function, pain and medication use outcomes of radiofrequency ablation for lumbar facet syndrome. Int $J$ Anesth Anesth 2(2)pii: 028, 2015

18. Mens JM: The use of medication in low back pain. Best Pract Res Clin Rheumatol 19(4):609-621, 2005

19. Nath S, Nath CA, Pettersson K: Percutaneous lumbar zygapophysial (Facet) joint neurotomy using radiofrequency current, in the management of chronic low back pain: A randomized double-blind trial. Spine 12:1291-1297, 2008

20. Pfingsten M, Lueder S, Luedtke K, Petzke F, Hildebrandt J: Significance of physical performance tests for patients with low back pain. Pain Medicine 7:1211-1221, 2014

21. Rambaransingh B, Stanford G, Burnham R: The effect of repeated zygapophysial joint radiofrequency neurotomy on pain, disability, and improvement duration. Pain Medicine 9:1343-1347, 2010

22. Richardson C, Hides J: Low back disorders: Evidence-based prevention and rehabilitation. British Association of Sport and Excercise Medicine 1:76, 2004

23. Wong AY, Parent EC, Funabashi M, Kawchuk GN: Do changes in transversus abdominis and lumbar multifidus during conservative treatment explain changes in clinical outcomes related to nonspecific low back pain? A systematic review. J Pain 15(4):377.e1-35, 2014

24. van Kleef M, Barendse GA, Kessels A, Voets HM, Weber WE, de Lange S: Randomized trial of radiofrequency lumbar facet denervation for chronic low back pain. Spine (Phila Pa 1976) 24(18):1937-1942, 1999

25. Yakut E, Duger T, Oksuz C, Yorukan S, Ureten K, Turan D, Frat T, Kiraz S, Krd N, Kayhan H: Validation of the Turkish version of the Oswestry Disability Index for patients with low back pain. Spine 5:581-585, 2004 